\title{
Amado Luiz Cervo e a historiografia brasileira de relações internacionais
}

\author{
Paulo Roberto de Almeida ${ }^{1}$ \\ Professor em Direito do Centro Universitário de Brasília (Uniceub) \\ pralmeida@me.com
}

Como citar este artigo: ALMEIDA, Paulo Roberto. "Amado Luiz Cervo e a historiografia brasileira de relações internacionais", Intelligere, Revista de História Intelectual, n¹0, pp. 1-14. 2020. Disponível em $<$ http://revistas.usp.br/revistaintelligere $>$. Acesso em dd/mm/aaaa-

Resumo: Ensaio em torno da historiografia brasileira de relações internacionais, política externa e história diplomática, com foco especial na obra acumulada pelo professor emérito da Universidade de Brasília (UnB) Amado Luiz Cervo, que se consagrou como paradigma da produção histórica nessas áreas, inclusive em perspectiva comparada com outros países da América Latina, com destaque para a Argentina. São referidas suas principais obras produzidas desde os anos 1970 até o período recente, quando produziu trabalhos de síntese nesses campos.

Palavras-chave: Amado Cervo; Historiografia brasileira; Relações internacionais; História diplomática.

\section{Amado Luiz Cervo and the Brazilian international relations historiography}

Abstract: Essay about the Brazilian historiography of international relations, external policy and diplomatic history, with an emphasis on the work of Emeritus professor of the University of Brasilia (UnB) Amado Luiz Cervo, who has distinguished himself as a paradigm in the historical production in those areas, including in a comparative perspective with Latin American neighbors, in especial Argentina. His many works published since the 1970s are

\footnotetext{
${ }^{1}$ Paulo Roberto de Almeida é diplomata de carreira no Ministério das Relações Exteriores; professor nos programas de mestrado e doutorado em Direito do Centro Universitário de Brasília (Uniceub); editor da Revista do IHG-DF; Email: pralmeida@me.com; site pessoal: www.pralmeida.org; http://orcid.org/0000-0003-2332-6233.
} 
subject to a brief presentation, up to our days, when he produced comprehensive works in those areas.

Keywords: Amado Cervo; Brazilian historiography; International relations; Diplomatic history.

A historiografia brasileira das relações internacionais exibe, ela própria, uma longa história, tanto no plano de seus métodos, em evolução constante desde o século XIX, quanto no de seu objeto, que é obviamente constituído pelas relações exteriores do Brasil e pela sua diplomacia, ou seja, a atividade do corpo profissional que a distinguiu desde cedo pela alta qualidade de seus integrantes, vários deles com estatura de estadistas. Não foi talvez o caso do próprio patrono da historiografia brasileira, Francisco Adolfo de Varnhagen (1972; 1975), que produziu uma história basicamente oficial, defendendo com base em documentos de governo as ações e posições dos governos portugueses nas relações com as demais potências envolvidas nas questões diplomáticas das colônias da América ibérica, mas apenas durante o período colonial e até a independência do Brasil. A diplomacia do primeiro Império e do Segundo Reinado foi abordada, num primeiro momento, por historiadores estrangeiros - o inglês Robert Southey (1810-1819) e o alemão Heinrich Handelmann (1865) -, que enfrentaram restrições de membros do Instituto Histórico e Geográfico Brasileiro, fundado em 1838.

Nos anos seguintes, a história da política externa, incluída em obras de história geral do Brasil, foi feita por historiadores amadores, por alguns autodidatas, ou até pelos próprios diplomatas, a exemplo do patrono da diplomacia brasileira, o Barão do Rio Branco, que escreveu uma Esquisse de l'Histoire du Brésil, para a Exposição Universal de Paris, de 1889, incluído como capítulo 5 da obra editada por Santa Anna Nery: Le Brésil en 1889. Rio Branco foi mais do que um historiador diplomático, uma vez que ele mesmo ajudou a fazer a história do Brasil, primeiro como defensor das fronteiras do país, em pendências arbitrais ou negociações diretas, depois como chanceler durante dez longos anos.

Nessa época, a historiografia diplomática esteve representada sobretudo pelo diplomata Manuel de Oliveira Lima, cujas obras sobre a transição brasileira para o status de nação independente - $O$ Reconbecimento do 
Império (1901); D. João VI no Brasil (1945); O Movimento da Independência; O Império Brasileiro (1822-1889) (1958), entre várias outras - ainda hoje sustentam o teste do tempo. $\mathrm{Na}$ sua sequência, o trabalho foi retomado pelos próprios membros do IHGB ou por acadêmicos com experiência política, a exemplo de Pandiá Calógeras, cuja obra em três volumes - A Política Exterior do Império (1929-1932; 1989; 1998) - cobre, na verdade, toda a história de Portugal, a formação de seu império americano e, aí sim, a política exterior do novo Estado independente, mas só até a derrubada de Rosas (1853). A produção historiográfica já se tinha profissionalizado amplamente, na primeira metade do século XX, mas a história das relações exteriores continuava a ser escrita por diplomatas ou por acadêmicos estreitamente vinculados ao establishment diplomático, como os professores do Instituto Rio Branco, criado em 1945. Estão nesse caso, o historiador Hélio Vianna (1961) e o geógrafo Delgado de Carvalho (1959; 2016), todos dois autores de obras de título idêntico: História Diplomática do Brasil, ambas publicadas no mesmo período. O historiador José Honório Rodrigues também deu aulas no IRBr no decorrer dos anos 1950, mas sua apostila de história diplomática só foi publicada em meados dos anos 1990, por iniciativa do historiador Ricardo Seitenfus (1995).

O manual de Delgado de Carvalho permaneceu durante décadas como a obra básica de estudo para os candidatos à carreira diplomática, mas ela tinha se tornado praticamente rara, por dispor de uma única edição, a original, a despeito do lento acumular de novos trabalhos de pesquisa, tanto por parte de diplomatas profissionais, quanto de historiadores da academia, duas comunidades que nem sempre se falaram, em parte devido aos desencontros políticos ao longo do regime militar (1964-1985). No campo específico da história da política externa do Brasil, o campo foi bastante renovado a partir dos trabalhos de acadêmicos que estavam terminando dissertações e teses no exterior, a exemplo de Gerson Moura (1980; 1991), de Maria Regina Soares de Lima (2013), de Ricardo Seitenfus (1985) e vários outros.

Nos anos 1970 começaram a aparecer cursos de graduação (UnB) ou de pós-graduação (PUC-Rio) especializados em temas de relações internacionais, nas duas vertentes clássicas, ciência política e história, com bastante osmose entre ambas. Foi nesse contexto que começaram a ganhar destaque os trabalhos, numa primeira fase de modo discreto, depois com maior 
audiência, produzidos no âmbito do Departamento de História da UnB, graças sobretudo aos esforços individuais do professor do Amado Luiz Cervo, que recém retornava de estudos pós-graduados na França. Desse período resultou seu primeiro livro editado comercialmente: Contato entre civilizaçôes (1975), um estudo sobre a conquista e a colonização espanhola das Américas. É dessa época, também, um artigo que dá início a uma vasta produção especializada: “Os primeiros passos da diplomacia brasileira" (1978).

O Departamento de História da UnB se fundiria, mais adiante, com o de Ciência Política, para constituir o Instituto de Relações Internacionais, responsável, ao longo das últimas décadas, por uma massa impressionante de pesquisas e publicações, que alcançaram renome mundial e internacional. Com vários outros professores, da $\mathrm{UnB}$ e parceiros em projetos de pesquisa sobre as relações internacionais do Brasil, o pequeno grupo original de historiadores constituiu o núcleo de uma grande comunidade de acadêmicos voltados para a historiografia das relações internacionais do Brasil, mas não apenas nesse campo, pois que abrangendo outras vertentes de estudo, inclusive em cooperação com os diplomatas. Mesmo se o trabalho de pesquisa histórica em temas de relações exteriores não seguiu uma escola específica no plano da metodologia, como é mais frequente de ocorrer com os modelos teóricos dos seus colegas da ciência política, esse grupo da UnB, mas mais especificamente o professor Amado Cervo, demonstrou confessada adesão à metodologia de Renouvin e Duroselle e, de modo geral, à escola francesa de história das relações internacionais.

Amado Cervo foi, precisamente, um dos representantes mais distinguidos das novas correntes da pesquisa universitária, combinando rigor na consulta às fontes primárias e um tratamento propriamente "social" (no seu sentido amplo, isto é, compreendendo também os aspectos políticos e econômicos) da história diplomática, considerada como parte integrante da história "global" do País. É dele o primeiro trabalho exaustivamente documentado sobre o importante papel do Parlamento na condução das relações exteriores do Brasil, ao desvendar, em O Parlamento Brasileiro e as Relações Exteriores, 1826-1889 (1981), o envolvimento do Legislativo na formulação, implementação e controle da política externa durante todo o período monárquico. Amado Cervo já tinha assinado com o professor 
Clodoaldo Bueno, da UNESP, Campus de Marília, um utilíssimo (ainda que sintético) livro sobre A Política Externa Brasileira, 1822-1985 (1986), uma espécie de ensaio geral à obra mais completa que ambos publicaram recentemente: História da Política Exterior do Brasil (1992; 2020).

Essa obra marcou época na bibliografia recomendada para o estudo da diplomacia e da política externa do Brasil, passando a ser utilizado por praticamente todos os candidatos ao exame de ingresso na carreira diplomática nos trinta anos seguintes, até ser possivelmente confrontado à obra mais recente do embaixador Rubens Ricupero, professor durante anos no curso de graduação e pós em relações internacionais da UnB: $A$ diplomacia na construção do Brasil, 1750-2016 (2017). No intervalo, Amado Cervo, solitariamente ou em colaboração, produziu muitas outras obras, entre as quais pode ser citada uma do mesmo ano em que foi publicado o manual-padrão: Relações Históricas entre o Brasil e a Itália: o papel da diplomacia (1992), um excelente racconto storico sobre os altos e baixos do relacionamento bilateral, sobretudo do ponto de vista dos homens que o fizeram.

Não seria o caso de retomar aqui as características e virtudes da "nova história diplomática" inaugurada por Cervo e Bueno. Caberia, entretanto, sublinhar a metodologia "renouviniana" no trabalho com as fontes primárias, uma bem-vinda ênfase nas questões econômicas do relacionamento externo, a valorização do multilateralismo - tema praticamente inexistente nos manuais tradicionais - e a adoção de uma perspectiva de largo curso na identificação das grandes fases da política externa: a "conquista e o exercício da soberania" (para a época imperial), "dos alinhamentos ao nacional-desenvolvimentismo" (para o período republicano até 1964) e o "nacionalismo pragmático" (para a fase recente). Ambos os autores parecem aderir às concepções comuns à maior parte dos historiadores universitários, tendentes a acreditar que as relações internacionais do Brasil se movem alternativamente entre o paradigma "liberalconservador" - por definição contrário ao "interesse nacional" - e o projeto "nacional-desenvolvimentista", que é sempre valorizado como sendo uma espécie de nec plus ultra da ideologia da diplomacia brasileira.

Ampliando seu relacionamento internacional - tendo já ocupado uma das vice-presidências da Comissão de História das Relações Internacionais -, Amado Cervo ajudou a organizar muitos seminários com convidados do 
exterior, sobretudo da França e da Argentina, a partir dos quais vários livros foram organizados por ele ou em colaboração: O Desafio Internacional: a política exterior do Brasil de 1930 a nossos dias. Brasília (1994); Relações Internacionais dos Países Americanos: vertentes da História (1994); Le Brésil et le Monde: pour une histoire des relations internationales des puissances emergentes (1998); Relações internacionais da América Latina (2001), livro no qual voltou a tratar dos velhos e novos paradigmas das diplomacias da região; $O$ crescimento das relações internacionais no Brasil (2005). Com o historiador argentino Mario Rapoport, ele organizou uma História do Cone Sul (1998), também publicado na Argentina como El Cono Sur: una História común (2002). Com o diplomata e historiador português, José Calvet de Magalhães, organizou o volume Depois das caravelas: as relaçoes entre Portugal e Brasil, 1808-2000 (2000), no quadro das comemorações pelos 500 anos do Descobrimento.

Uma de suas reflexões mais importantes, justamente elaborada a partir de seus muitos trabalhos anteriores de pesquisa em arquivos e com base na literatura secundária, foi oferecida neste livro, que ele mesmo considera um de seus mais importantes, antes da síntese mais recente, sobre a qual se falará ao final: Inserção Internacional: formação dos conceitos brasileiros (2008). Essa obra, à diferença dos livros mais empiricamente embasados, se dedica à elucidação de conceitos e paradigmas, com base na história, mas buscando transcender o fluxo descritivo daqueles outros trabalhos para penetrar nas continuidades e rupturas das grandes linhas da política externa brasileira em praticamente dois séculos de afirmação: 1808 foi o ano em que a política externa da "metrópole" - retirada da península ibérica pela invasão napoleônica do ano anterior, passa a ser feita a partir do Rio de Janeiro.

Ele está organizado em três partes distintas, mas que se complementam: a primeira se dedica a seguir as transições entre diferentes fases da política externa no plano histórico; a segunda se organiza tematicamente em torno das grandes questões do multilateralismo, da globalização, da defesa e segurança, assim como à integração das economias nacionais em blocos comerciais, no caso do Brasil representado pelo Mercosul; a terceira, finalmente, recolhe essas diferentes dimensões da política externa e das relações internacionais do Brasil para examinar as bases da atuação internacional do país, em tornos dos eixos de grandes parcerias (Estados 
Unidos e grandes potências) e da projeção do país em outros continentes. O que faz Amado Cervo, de certo modo, é defender a ideia de que o Brasil, e os estudiosos nacionais (em especial os da UnB), já superaram a fase de "substituição de importações" - quando se analisava as relações exteriores do país com base em modelos analíticos importados - e passaram a construir uma disciplina dotada de escopo e métodos próprios.

Os artigos de Amado Cervo em revistas especializadas ou suas colaborações a obras coletivas são por demais numerosos para serem apresentados em sua totalidade neste espaço. Cabe mencionar, no entanto, dois deles: "Entre l'Europe et l'Amérique, la Politique Extérieure du Brésil au XIX Siècle (1808-1912)" (1999) e o capítulo em livro organizado por ocasião do centenário da posse do Barão do Rio Branco como chanceler: "O Barão do Rio Branco e a modernização da agenda brasileira" (2002). Vale também referir que grande parte dos ensaios mais recentes abordam temas de "histoire immédiate", focando as relações internacionais do Brasil nos diversos governos brasileiros desde os anos 1990 até a atualidade, de que são exemplos artigos publicados na Revista Brasileira de Política Internacional: "Sob o signo neoliberal: as relações internacionais da América Latina" (2000); "Relações Internacionais do Brasil: um balanço da era Cardoso", (2002); "A política exterior: de Cardoso a Lula" (2003).

Não obstante importantes trabalhos de pesquisa e obras publicadas por historiadores de grande relevância na história da política externa e da diplomacia brasileira é forçoso reconhecer que poucos acadêmicos, no Brasil exibiram, como o professor Amado Cervo, uma tal relação de bons serviços prestados à causa do internacionalismo acadêmico e da pesquisa histórica de excelente qualidade, serviços sempre marcados pela honestidade intelectual, pela dedicação ao conhecimento exaustivo dessas questões e pelo compromisso didático sempre renovado a cada semestre de atividades docentes. Tais atributos projetaram sobre esse campo de estudos no Brasil uma marca de excelência que há muito ultrapassou as fronteiras do país. Suas muitas obras - livros, artigos, ensaios em volumes coletivos, participação em seminários acadêmicos e mesas redondas - constituem menções obrigatórias na bibliografia de referência. 
Não sem méritos, quando foram transferidos do Rio de Janeiro para Brasília, em 1992-93, o Instituto Brasileiro de Relações Internacionais (fundado em 1954) e sua publicação central, a Revista Brasileira de Política Internacional (a mais antiga da área, criada em 1958), Amado Cervo foi unanimemente escolhido como editor do periódico, exercendo-se durante vários anos em sua primeira fase de Brasília. Não sem razão, tampouco, sua produção ocupou largo espaço num artigo de síntese bibliográfica elaborado para um dos primeiros números dessa revista em sua fase de Brasília: "Estudos de Relações Internacionais do Brasil: Etapas da produção historiográfica brasileira, 19271992" (Almeida, 1993). Também em função de sua vasta produção ele foi legitimamente homenageado com o título de Professor Emérito da UnB.

Aposentado, mas não inativo, ele continuou a produzir, e não só atualizando o manual com Clodoaldo Bueno (já em sexta edição; 2020), mas igualmente um livro síntese, quase que de inspiração hegeliana, em seu título: $O$ Espírito das Relacõoes Internacionais (2020). Os acréscimos efetuados por Amado Cervo ao manual conjunto sobre a Politica Exterior do Brasil chegam a 2020, e cobrem, portanto, algumas das tomadas de posição da nova diplomacia bolsonarista, em grande medida influenciada pelas posturas claramente ineptas na área das relações internacionais daquele que passa por conselheiro ideológico do governo Bolsonaro, um sofista expatriado sem qualquer qualificação no setor: antiglobalismo, antimultilateralismo, impregnação religiosa na diplomacia, hostilização aberta a governos supostamente de esquerda, adesão subserviente ao governo do presidente Trump e outras do mesmo tipo. Os novos parágrafos são enfeixados por novos conceitos claramente expressados, enfeixados por um título absolutamente explícito a essa última parte: "Estagnação e atraso global: 2014-2020", sendo que as novas considerações abrangem as questões mais relevantes da agenda diplomática do Brasil nas novas condições do sistema internacional: a estagnação econômica como tendência, o multilateralismo e comércio exterior, a vizinhança do Brasil e suas relações com as grandes potências.

As novas referências bibliográficas, correspondendo ao período recente coberto, e que foram acrescentadas ao final do livro, se referem mais exatamente a matérias da imprensa, mais até do que a livros ou artigos acadêmicos, sendo que diversas são até mais expositivas do que analíticas, dada 
ao caráter de "história imediata" dos eventos selecionados como exemplos. Encontra-se nesse caso o assassinato de um general iraniano no Iraque, em janeiro de 2020, quando o Itamaraty - talvez não exatamente o ministério, mas seus controladores, amadores - lança uma nota confusa, condenando o terrorismo, não o atentado americano, contrário, em princípio, ao direito internacional; esse exemplo serve para apoiar, em seguida, a caracterização também feita por um jornalista, evidenciando o alinhamento cego do Itamaraty ao governo Trump. Também nesse impulso de história imediata, estão referidos equívocos do novo governo com os temas do meio ambiente, das relações com a China e outros, entre eles os atritos com os vizinhos, em primeiro lugar a Venezuela.

Já o novo livro, O Espírito das Relações Internacionais, em fase de publicação, se apresenta como uma espécie de síntese conceitual de todo o itinerário intelectual de Amado Cervo em sua condição de pesquisador das relações internacionais do Brasil, mas pode também servir de locus reflexivo sobre como ele concebe o sistema internacional de forma geral, o que já é evidente pelos títulos de seus onze capítulos: valores, segurança, defesa, interesses, sobrevivência, convivência, guerra, teorias, conceitos, "pedaços" (que se referem a países e regiões) e, finalmente, itinerários (ou seja, ritmos alternativos de desenvolvimento entre os países, os avançados e os que permanecem atrasados, aquilo que os economistas historiadores chamam de divergência e convergência na marcha das economias). Esse último capítulo se ocupa, portanto, das assimetrias entre os países - poder econômico e militar, autonomia tecnológica, etc. -, o que constitui o próprio núcleo das relações internacionais, e também dos intercâmbios globais. As "forças profundas" podem ser influenciadas por fatores contingentes, como se sabe.

A introdução ao livro (comunicada em seu formato pré-impressão) já abre por uma constatação que poderia ser de senso comum, mas que deve ser reafirmada, para quem pretenda escrever sobre as relações internacionais a partir das sólidas bases da história, da economia, das relações de poder, como elas se exercem na realidade, e não com base em modelos teóricos, por mais elegantes que eles possam ser: "As relações internacionais assentam sobre uma base empírica." Ou seja, não se pode partir dos fatos concretos que subjazem às ações dos Estados. Mas, ele acrescenta logo em seguida: 
Existem, contudo, impulsos que movem os Estados, as nações e os demais agentes da sociedade, quando agem externamente. Os impulsos correspondem a comandos superiores do movimento das relações internacionais. Esses comandos superiores pairam sobre a empiria, ou seja, pairam sobre os fatos, as tendências e as versões narrativas das relações internacionais. Os comandos superiores conferem inteligibilidade, portanto conduzem à compreensão do complexo movimento das relações internacionais.

Em outros termos, esses impulsos podem corresponder a motivações pessoais dos agentes primários das relações de poder, que podem ser dirigentes orientados por certas ideias, determinados objetivos, ambições ou até percepções ou reações a ações de países supostamente adversários ou concorrentes numa determinada esfera de influência. Confirmando, aliás, sua precoce adesão à visão francesa das relações internacionais - mais exatamente, às chamadas "forças profundas" sempre referidas por Renouvin - ele estabelece quais são as premissas que orientaram suas reflexões sobre o "espírito" dessas relações:

O estudo acerca do espírito das relações internacionais navega sobre águas profundas e horizontes longínquos, sobre aqueles componentes de percurso que imprimem à rota cuidados, rumo e orientação. O estudo mira a chegada, o destino: fornece explicação, inteligibilidade e compreensão para o movimento das relações internacionais.

Sua preocupação básica, nesta obra recente, talvez a última de uma longa carreira, é com o objetivo de "conferir inteligibilidade e explicação ao movimento dos agentes das relações internacionais", o que nem sempre é possível, dada a multiplicidade de "impulsos" ou "opiniões" emergindo naturalmente em ambientes democráticos ou autoritários, o que redunda, parafraseando um famoso economistas, no aparecimento do equivalente político, ou geoestratégico, daqueles fatores contingentes, e inesperados, simbolizados pela figura dos "cisnes negros". Daí as guerras, que podem surgir mesmo na ausência de algum planejamento de "conquista" ou "retaliação", e sim por acidentes, como tantas vezes ocorrido na história: talvez a Grande Guerra, talvez a guerra de Tróia. O final de sua introdução expressa os seus objetivos principais nesta obra, que deve estar à disposição dos leitores dentro em breve:

As relações internacionais são complexas. Dar-lhes inteligibilidade e compreensão é o alvo dos estudos da área. Este livro lida com a pergunta essencial: quais são os comandos 
superiores que agem como impulsos na origem e determinam ao termo o resultado da ação externa dos agentes que se movimentam pelo mundo?

O capítulo conclusivo retoma, ainda mais sinteticamente, cada um dos conceitos e caracterizações expressos nos onze capítulos substantivos sobre os grandes movimentos das relações internacionais, que Amado imputa aos "comandos superiores", que orientam os agentes, justamente aqueles onze examinados ao longo do livro. Suas conclusões finais são uma condensação dos argumentos expostos, e podem ser reproduzidas aqui:

Os onze comandos superiores das relações internacionais
encontram dois moderadores: o multilateralismo do direito
internacional e as organizações governamentais e não
governamentais internacionais.
Em suma: o espírito das relações internacionais é feito de
comandos superiores que pairam sobre agentes e movimento,
como causalidade e explicação soberanas do miúdo dos fatos e
das tendências. Conduzem ao conhecimento e fundamentam a
decisão certa dos agentes.

O fato de colocar o "multilateralismo do direito internacional", bem como as organizações intergovernamentais, tanto quanto as ONGs da sociedade civil, na condição de "moderadores" dos "impulsos" dos agentes estatais de certa forma coloca Amado Cervo num terreno praticamente oposto aos princípios de atuação da diplomacia bizarra sendo atualmente implementada pelo governo Bolsonaro. A esse propósito, os "comandos superiores" que "pairam sobre agentes e movimento" dessa atual política externa e diplomacia não parecem ser aqueles que, segundo sua frase final, "conduzem ao conhecimento e fundamentam a decisão certa" desses agentes. A julgar pelos desatinos, equívocos e virtual rejeição universal tanto do presidente atual, quanto de seu chanceler acidental, assim como da política externa (ou falta de) que parece se contrapor a todas as tendências e padrões exibidos nos últimos dois séculos pela diplomacia brasileira - tal como exposta e analisada nas muitas obras de Amado Cervo e associados -, tais comandos que pairam sobre os atuais "agentes" não exibem absolutamente nada de superiores, apenas revelam certos preconceitos ultrapassados e péssimos instintos primários, não fundamentados em nenhum conhecimento ou dados da realidade. Possivelmente, numa sétima edição do manual a quatro mãos sobre a Politica Exterior do Brasil ou numa segunda edição deste seu livro-síntese, 
Amado Cervo exporá sua avaliação do momento presente da política externa e da diplomacia brasileira com base nos seus critérios analíticos já consolidados.

\section{Referências:}

ALMEIDA, P. R. "Estudos de Relações Internacionais do Brasil: Etapas da produção historiográfica brasileira, 1927-1992”, Revista Brasileira de Política Internacional, 36-1, 1993.

CALÓGERAS, P. A Política Exterior do Império (3 vols., 1929-1932); novas edições fac-similares: Brasília: Câmara dos Deputados, Introdução por João Hermes Pereira de Araújo. 1989; Brasília: Senado Federal, 1998, 3 vols.

CERVO, A. L. Contato entre civilizações. São Paulo, McGraw-Hill, 1975.

CERVO, A. L. "Os primeiros passos da diplomacia brasileira", Relações Internacionais, 1-3, 1978.

CERVO, A. L. O Parlamento Brasileiro e as Relações Exteriores, 1826-1889. Brasília, Editora da UnB, 1981.

CERVO, A. L. Relações Históricas entre o Brasil e a Itália: o papel da diplomacia. Brasília-São Paulo: Editora da UnB-Istituto Italiano di Cultura, 1992.

CERVO, A. L. "Estudos de Relações Internacionais do Brasil: Etapas da produção historiográfica brasileira, 1927-1992”, Revista Brasileira de Política Internacional, 36-1, 1993.

CERVO, A. L. "Entre l'Europe et l'Amérique, la Politique Extérieure du Brésil au XIX Siècle (1808-1912)", In: MATTOSO, K. Q.; SANTOS, I. M.; ROLLAND, D. (orgs.), Le Brésil, l'Europe et les Équilibres Internationaux. Paris : Presses de l'Université de Paris-Sorbonne, 1999.

CERVO, A. L. "Sob o signo neoliberal: as relações internacionais da América Latina", Revista Brasileira de Política Internacional, 43-2, 2000; https://doi.org/10.1590/S0034-73292000000200001.

CERVO, A. L. "Relações Internacionais do Brasil: um balanço da era Cardoso", Revista Brasileira de Política Internacional, 45-1, 2002; http://dx.doi.org/10.1590/S0034-73292002000100001.

CERVO, A. L. "A política exterior: de Cardoso a Lula", Revista Brasileira de Política Internacional, 46-1, 2003; http://dx.doi.org/10.1590/S003473292003000100001 .

CERVO, A. L. "O Barão do Rio Branco e a modernização da agenda brasileira” In: CARDIM, C. H.; ALMINO, J. (orgs.). Rio Branco, a América do Sul e a Modernização do Brasil. Brasília: Funag, 2002. 
CERVO, A. L. Inserção Internacional: formação dos conceitos brasileiros. Brasília, Editora da UnB, 2008.

CERVO, A. L. O Espírito das Relações Internacionais. Brasília: Editora da UnB, em publicação; 2020.

CERVO, A. L. (org.). O Desafio Internacional: a política exterior do Brasil de 1930 a nossos dias. Brasília: Editora da UnB, 1994.

CERVO, A. L. (org.). Relações internacionais da América Latina. Brasília: Editora da UnB, 2001.

CERVO, A. L.; BUENO, C. A Política Externa Brasileira, 1822-1985. São Paulo, Ática, 1986.

CERVO, A. L.; BUENO, C. História da Política Exterior do Brasil 1ª Ed.; São Paulo, Ática, 1992; 6a . Ed.; Brasília: Editora da UnB, 2020.

CERVO, A. L.; DÖPKE, W. (orgs.). Relações Internacionais dos Países Americanos: vertentes da História. Brasília: Editora da UnB, 1994.

CERVO, A. L.; ROLLAND, D. ; SARAIVA, J. F. S. (orgs.). Le Brésil et le Monde : pour une histoire des relations internationales des puissances émergentes. Paris : L'Harmattan, 1998.

CERVO, A. L.; SARAIVA, J. F. S. (orgs.). O crescimento das relações internacionais no Brasil. Brasília: Editora da UnB, 2005.

CERVO, A. L.; MAGALHÃES, J. C. de (orgs.). Depois das caravelas: as relações entre Portugal e Brasil, 1808-2000. Brasília: Editora da UnB, 2000.

CERVO, A. L.; RAPOPORT, M. (orgs.) História do Cone Sul. Brasília: Editora da UnB, 1998; ed. argentina: El Cono Sur: una História común. Buenos Aires: Fondo de Cultura Económica, 2002.

DELGADO DE CARVALHO, C. História Diplomática do Brasil. São Paulo: Companhia Editora Nacional, 1959; nova edição pelo Senado Federal, 2016.

HANDELMANN, H. Geschichte von Brasilien (1865); traduzido e publicado: Rio de Janeiro: IHGB, 1931.

LIMA, M. O. O Reconhecimento do Império (História diplomática do Brasil). Paris-Rio de Janeiro: H. Garnier, 1901.

LIMA, M. O. D. João VI no Brasil. Prefácio de Octavio Tarquinio de Sousa. 2a . ed.; Rio de Janeiro: Livraria José Olympio Editora, 1945, 3 vols.

LIMA, M. O. O movimento da independência; O Império Brasileiro (18221889). $2^{a}$. ed. São Paulo: Melhoramentos, 1958.

MOURA, G. Autonomia na dependência: a política exterior brasileira de 1935 a 1943. Rio de Janeiro: Nova Fronteira, 1980. 
MOURA, G. Sucessos e ilusões: relações internacionais do Brasil durante e após a Segunda Guerra Mundial. Rio de Janeiro: Fundação Getúlio Vargas, 1991.

RICUPERO, R. A diplomacia na construção do Brasil, 1750-2016. Rio de Janeiro: Versal, 2017.

RIO BRANCO, B. Esquisse de l'Histoire du Brésil, in: NERY, S. A. Le Brésil en 1889 .

RODRIGUES, J. H.; SEITENFUS, R. Uma História Diplomática do Brasil, 1531-1945. Rio de Janeiro: Civilização Brasileira, 1995.

SEITENFUS, R. O Brasil de Getúlio Vargas e a Formação dos Blocos: 19301942. São Paulo: Companhia Editora Nacional, Coleção Brasiliana, 1985.

SOARES DE LIMA, M. R. The Political Economy of Brazilian Foreign Policy: Nuclear Energy, Trade and Itaipu. Brasilia: Funag, 2013.

SOUTHEY, R. History of Brazil. Londres: Longman; Hurst, Rees, and Orme, Paternoster-row, 1810-1819, 3 vols.

VARNHAGEN, F. A. História Geral do Brasil antes da sua separação e independência de Portugal. Revisão e Notas de Rodolfo Garcia. 8a. edição integral; São Paulo: Edições Melhoramentos, 1975.

VARNHAGEN, F. A. História da Independência do Brasil, até o reconhecimento pela antiga metrópole, compreendendo, separadamente, a dos sucessos ocorridos em algumas províncias até essa data (Anotada pelo Barão do Rio Branco, por uma Comissão do IHGB e pelo prof. Hélio Vianna). $6^{a}$ ed.; Brasília: Instituto Nacional do Livro, 1972.

VIANNA, H. História da República; História Diplomática do Brasil. $2^{a}$ ed.; São Paulo: Melhoramentos, 1961. 